\title{
HOW AWARE IS THE PUBLIC OF CARBON CAPTURE AND STORAGE?
}

\author{
Tom Curry ${ }^{1}$, David M. Reiner ${ }^{2}$, Stephen Ansolabehere ${ }^{3} \&$ Howard J. Herzog $^{1 *}$ \\ ${ }^{1}$ MIT Laboratory for Energy and the Environment, Cambridge, MA 02139 \\ ${ }^{2}$ Judge Institute of Management, Cambridge University, Cambridge, CB2 1AG, UK \\ ${ }^{3}$ MIT Department of Political Science, Cambridge, MA 02139
}

\begin{abstract}
In late September and early October 2003, we conducted a survey of public attitudes on energy use and environmental concerns. Over 1,200 people, representing a general population sample of the United States, responded. The survey asked seventeen questions about the environment, global warming, and climate changemitigation technologies. In addition, a full set of demographic data was provided for each respondent.

Goals of the survey included determining attitudes toward global warming and climate change mitigation technologies, the level of public understanding of global warming and the carbon cycle, and public awareness of carbon dioxide capture and storage (or carbon sequestration). The survey results show that the environment is not a top priority for the U.S. public and global warming is not the top environmental concern; there is much confusion concerning the carbon cycle and the causes of global warming; and less than $4 \%$ of respondents were familiar with the terms carbon dioxide capture and storage or carbon sequestration. It is hoped that results of this survey will be helpful in designing public outreach campaigns.
\end{abstract}

\section{Introduction}

In late September and early October 2003, we conducted a survey of public attitudes on energy use and environmental concerns. Seventy percent of those asked responded to the survey $(1,205$ people out of 1,710$)$, representing a general population sample of the United States.

Researchers at MIT and the University of Cambridge in collaboration with staff at Knowledge Networks, a consumer information company specializing in Internet-based public opinion surveys, designed the survey to reveal attitudes toward and understanding of carbon dioxide capture and storage (CCS) as part of broad range of questions about energy and the environment. The survey included seventeen questions plus an additional three demographic questions. Knowledge Networks provided 24 supplementary demographic variables from their database. The demographic variables included respondent characteristics such as age, location, education level, and income level. Four of the survey questions referred specifically to carbon capture and storage or carbon sequestration. Initial versions of the survey included more questions about CCS, but the focus shifted to reduce respondent bias toward or away from CCS. A detailed analysis of the survey responses and a copy of the full questionnaire are available in Public Awareness of Carbon Capture and Storage: A Survey of Attitudes toward Climate Change Mitigation [1].

Knowledge Networks has recruited an online research panel designed to be representative of the entire U.S. population and conducts their surveys using the Internet. Knowledge Networks recruits households for their membership panel using a probability sampling technique called random digit dialing [2]. Selected households are provided free hardware and Internet access. Each household receives identical hardware, even if they already own a computer. When drawing a random sample to complete a survey, Knowledge Networks draws from this large, national membership panel.

The survey responses are analyzed to answer the following questions:

- What are public attitudes toward global warming and climate change-mitigation technologies?

*Corresponding author: Tel. (617) 253-0688, Fax. (617) 253-8013, Email: hjherzog@mit.edu 
- What is the level of public understanding of global warming and carbon dioxide capture and storage (or carbon sequestration)?

- What is the effect of information (national energy usage and price data) on public preferences?

- What lessons do the survey results suggest for public outreach campaigns?

\section{Public Attitudes}

Four of the survey questions addressed general attitudes towards the environment or spending on the environment. Figure 1 shows public opinions on the issues facing the United States at the time of the survey. The survey included the 22 issues and asked the respondents to choose the three most important issues.

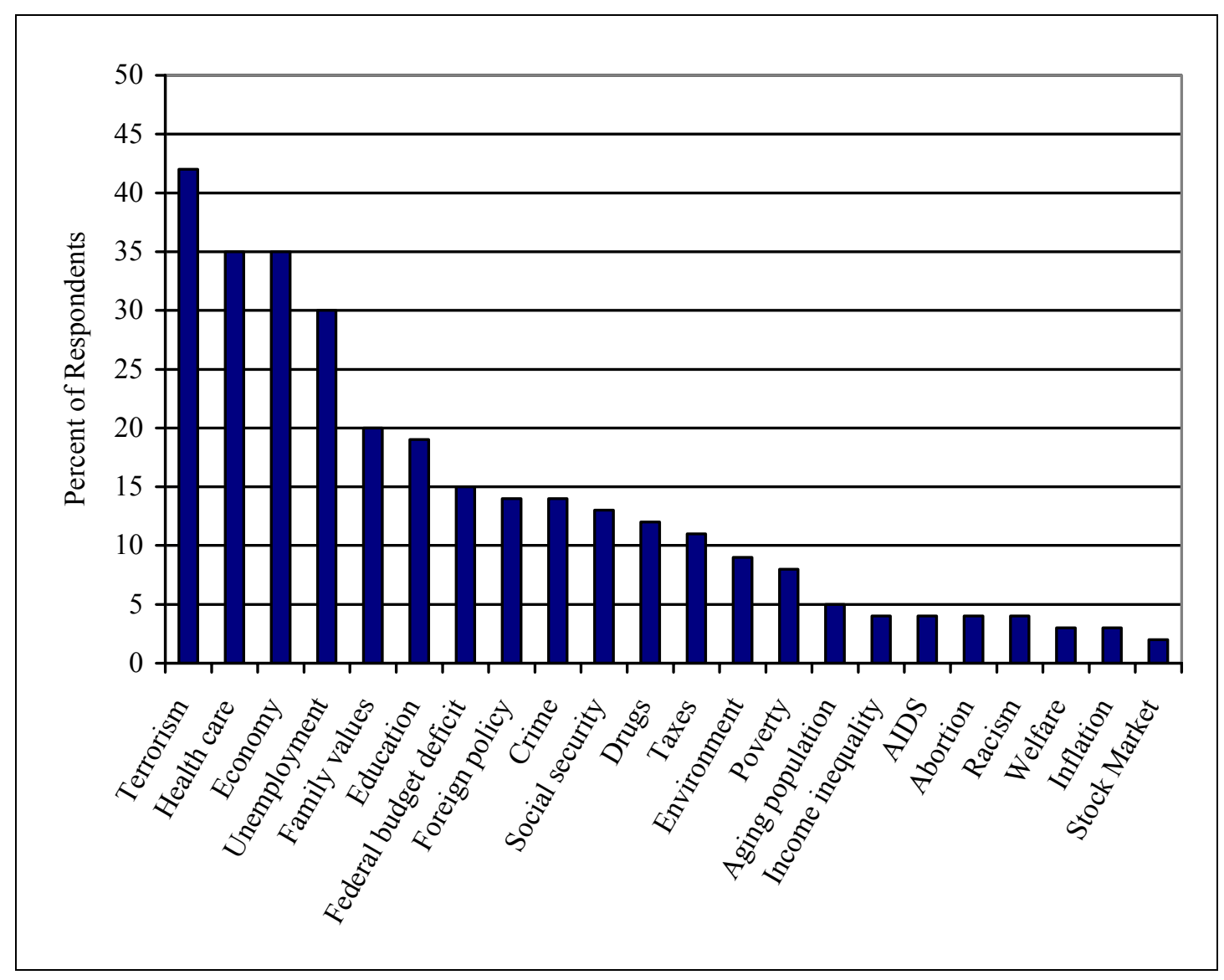

Figure 1. Response to: Consider the following issues. What are the three most important issues facing the U.S. today? Percentage of respondents including an issue in their top three are shown.

The environment ranks thirteenth on the list. The results are consistent with those Gallup reported for a similar timeframe [2]. Respondents who chose the environment in response to this question are considered concerned about the environment. Concern about the environment was not a strictly partisan issue. Of Republicans surveyed, 7.3\% listed the environment compared to $7.8 \%$ of Democrats. A higher number of independents, $17.5 \%$, said they were concerned about the environment.

Figure 2 shows public opinion about specific environmental problems. The survey included 10 environmental problems and asked respondents to choose the two most important issues facing the United States. 


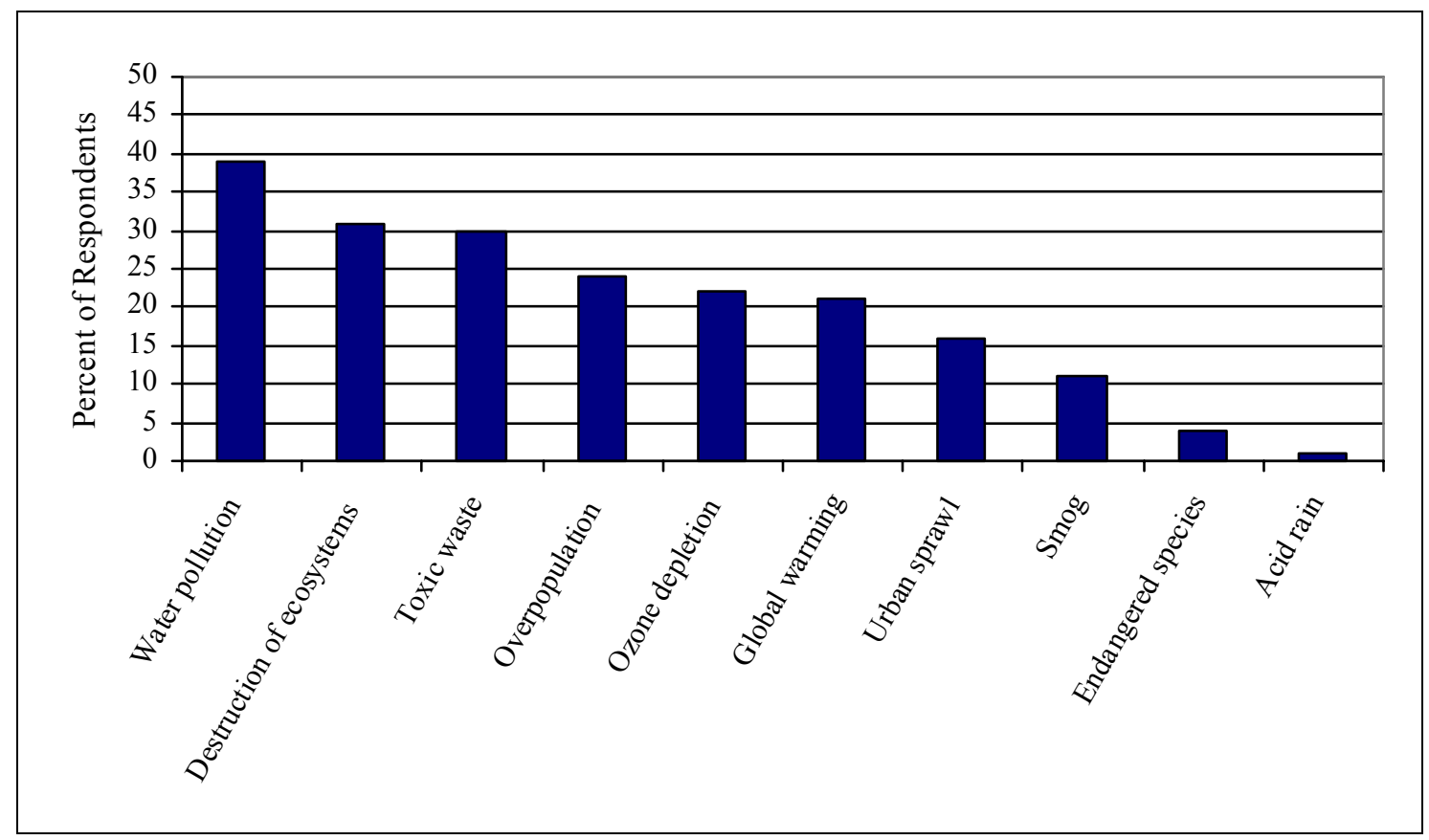

Figure 2. Response to: Consider the following environmental problems. Which is the most important problem facing the US today? Percentage of respondents including an issue in their top two are shown.

As the figure shows, global warming ranked sixth out of the issues in the survey. Among those who listed the environment as one of their top three concerns, global warming was the third highest ranked concern ( $27 \%$ ranked it as first or second) preceded by destruction of ecosystems (60\%) and water pollution (29\%). In a recent Gallup Poll (March 8-11, 2004, N=1,005 adults nationwide. Margin of error \pm 3 ), global warming ranked ninth on a list of 10 comparable environmental problems that respondents were worried about when asked "if you personally worry about this problem a great deal, a fair amount, only a little, or not at all. How much do you personally worry about [specific environmental problem]?" [3].

\section{Public Understanding}

A major concern when eliciting views on a subject such as the environment is the ability of the public to understand the policy options and the underlying issues. Figure 3 shows the results of a question focused on whether respondents had heard of or read about 10 different technologies or energy sources in the past year. The question included the list of technologies shown in the figure. Respondents could select as many technologies as they wished or could answer "none of these." Note that almost $17 \%$ of the sample selected "none of these". 


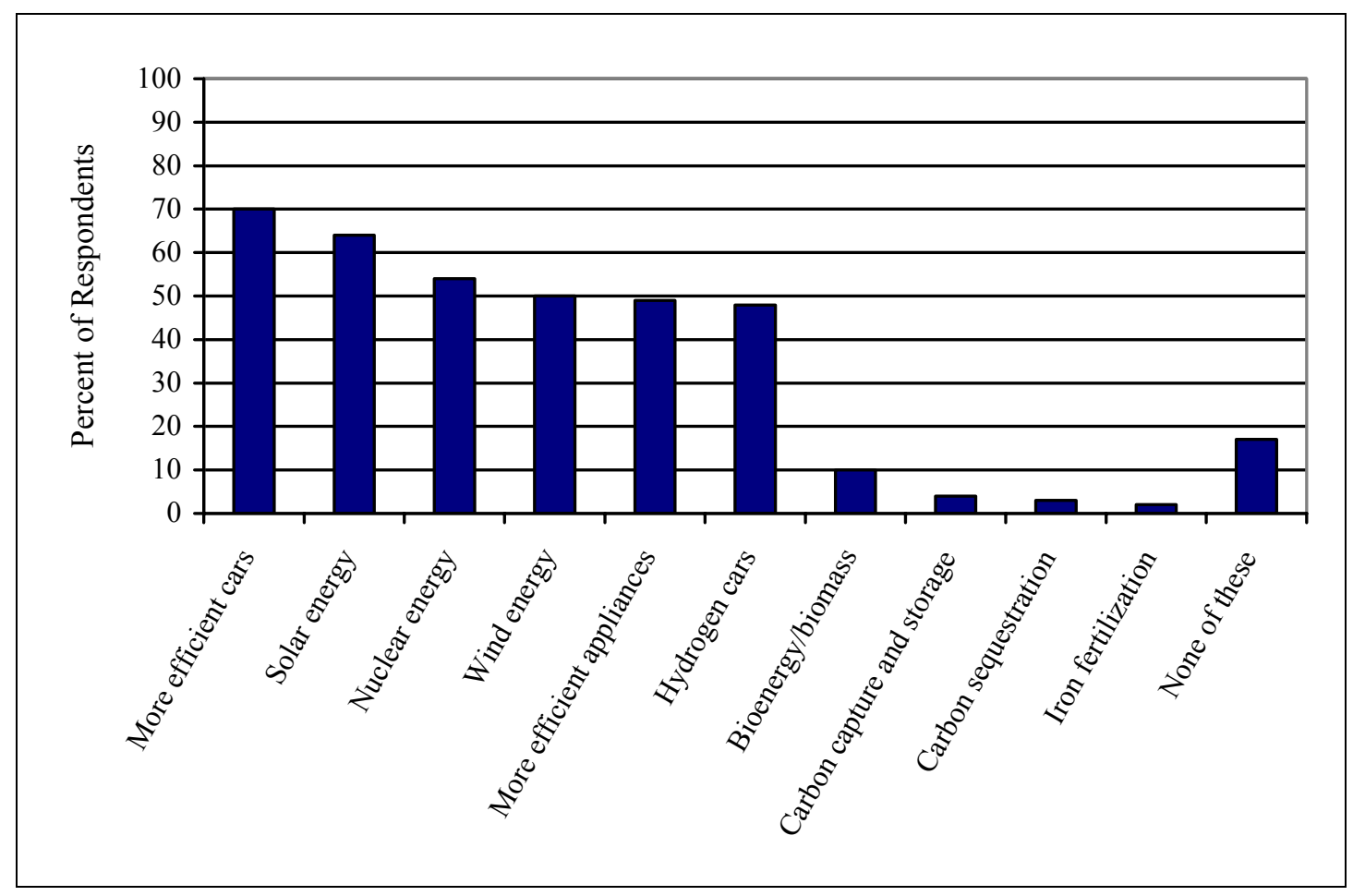

Figure 3. Response to: Have you heard of or read about any of the following in the past year? Check all that apply.

The recognition of carbon capture and storage and carbon sequestration is minimal. The only demographic indicator that distinguishes those who have heard of carbon sequestration and carbon capture and storage from those who have not heard of either is education. At the $90 \%$ confidence level, those who have heard of either of the technologies are slightly more educated.

This question is sensitive to the bias that respondents might say that they have heard of a particular item to give the expected answer or to appear knowledgeable. The possible presence of this bias makes low response rates for carbon capture and storage and carbon sequestration even more striking since polls will tend to overstate recognition. Clearly, very few people have heard of these technologies.

We constructed a question asking respondents to identify sources and sinks of $\mathrm{CO}_{2}$. The question asked if specific technologies or systems increased $\mathrm{CO}_{2}$, decreased $\mathrm{CO}_{2}$, or had no impact on $\mathrm{CO}_{2}$. Respondents could answer that they were not sure. Table 1 shows responses for selected technologies and systems.

Table 1. Response to: There is a growing concern about increasing levels of carbon dioxide in the atmosphere. How do you think the following contribute to these levels?

\begin{tabular}{lcccc}
\hline Technology or System & Increases $\mathbf{C O}_{\mathbf{2}} \mathbf{( \% )}$ & Decreases $\mathbf{C O}_{\mathbf{2}} \mathbf{( \% )}$ & No Impact (\%) & Not Sure (\%) \\
\hline Automobiles & 78 & 3 & 2 & 18 \\
Factories & 73 & 3 & 2 & 23 \\
Coal burning power plants & 70 & 2 & 3 & 25 \\
Home heating & 53 & 3 & 9 & 36 \\
Nuclear power plants & 30 & 8 & 20 & 43 \\
Trees & 7 & 66 & 8 & 19 \\
Oceans & 4 & 29 & 26 & 41 \\
Windmills & 3 & 21 & 49 & 27 \\
\hline
\end{tabular}


The public is generally correct about automobiles, coal burning power plants, and factories being sources of $\mathrm{CO}_{2}$. They are less certain about home heating being a source of $\mathrm{CO}_{2}$. Notably, the public is uncertain about nuclear power plants being $\mathrm{CO}_{2}$ sources and oceans being $\mathrm{CO}_{2}$ sinks. The misperception that nuclear facilities contributes to global warming found in many other studies $[4,5]$ has serious policy implications given the long-standing debate over nuclear power and the hopes of the nuclear industry for renewed support as a carbon-free alternative source of electricity.

Researchers often use the term "carbon sequestration" to refer to the uptake of $\mathrm{CO}_{2}$ by plants as trees. Table 1 shows that the public is largely familiar with the idea that trees uptake $\mathrm{CO}_{2}$ while Figure 3 shows that the public is unfamiliar with the term carbon sequestration. Thus, it is not the phenomenon of $\mathrm{CO}_{2}$ uptake by trees that is misunderstood but the term frequently used by experts to describe it.

The survey included a question specifically about carbon capture and storage and carbon sequestration. The question asked respondents to choose the environmental concern that carbon sequestration or carbon capture and storage is able to address. Respondents could choose more than one concern. Table 2 shows the responses.

Table 2. Response to: Please select if "carbon sequestration" or "carbon capture and storage" can reduce each of the following environmental concerns.

\begin{tabular}{lccc} 
Environmental Concern & Can Reduce (\%) & Does Not Reduce (\%) & Not Sure (\%) \\
\hline Smog & 29 & 3 & 68 \\
Water pollution & 23 & 5 & 72 \\
Global warming & 23 & 5 & 73 \\
Ozone depletion & 21 & 5 & 74 \\
Acid rain & 21 & 6 & 73 \\
Toxic waste & 16 & 8 & 76 \\
\hline
\end{tabular}

A large number of respondents were unsure about what environmental concern the technology addresses. In the entire sample, the number who answered the question correctly is within the margin of error. Less than $0.5 \%$ (5 respondents out of 1,205) answered the question correctly (marking "can reduce" for global warming and "not sure" or "does not reduce" for the remaining answers). Interestingly, about the same number of respondents (7) answered the question completely incorrectly (marking "not sure" or "does not reduce" for global warming and "can reduce" for all the other concerns). Over half the respondents (58\%) answered "not sure" for all the concerns.

The small number of respondents who said they had heard of carbon capture and storage $(n=46)$ were no more likely to answer the question correctly. However, they were more likely to attempt to answer the question. Only fourteen percent of those who had heard of carbon capture and storage answered "not sure" for all of the concerns. The results for the 3\% who said that they had heard of or read about carbon sequestration in the past year are similar to those who had heard of or read about carbon capture and storage.

\section{Effect of Price Information on Preferences}

The survey included a question asking about willingness of the respondent to pay more on his or her monthly electricity bill to "solve global warming." Respondents were asked "If it solved global warming, would you be willing to pay [dollar value] more per month on your electricity bill?" The first dollar value offered as a response was $\$ 5$. If the respondent answered yes, the dollar value increased to $\$ 10$. A second yes response increased the dollar value to $\$ 25$, followed by $\$ 50$, and $\$ 100$. Figure 4 provides a breakout of the responses. 


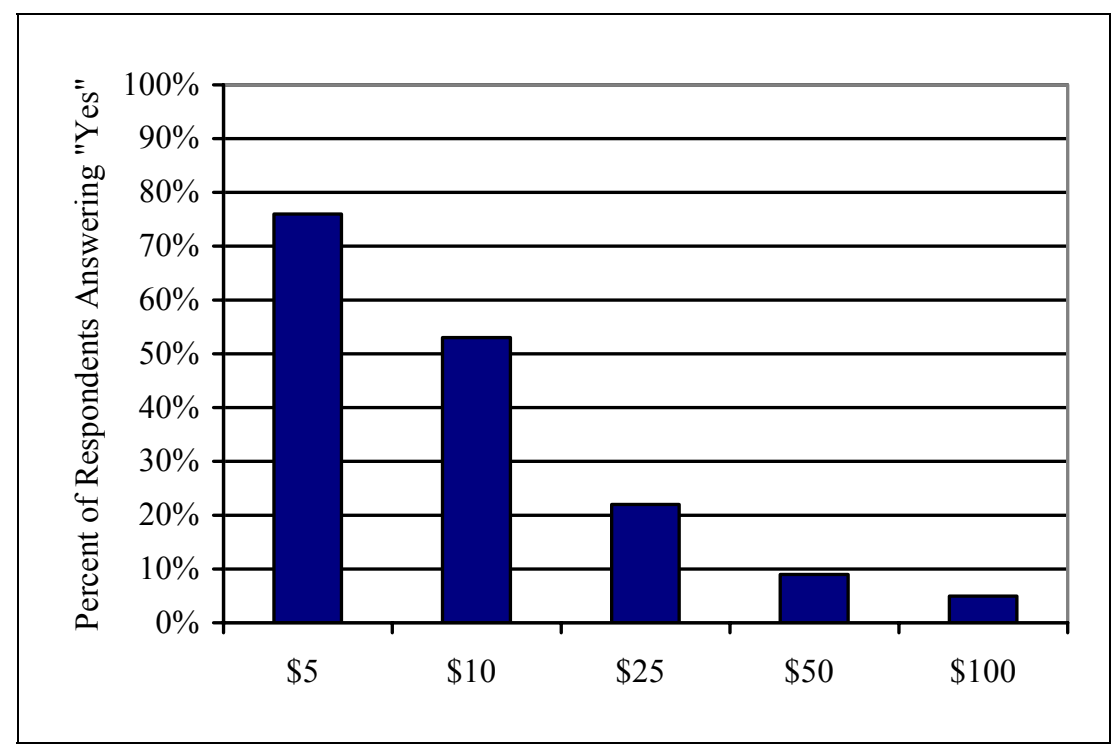

Figure 4. Response to: If it solved global warming, would you be willing to pay__ more per month on your electricity bill? Percentage of respondents who answered "yes" to each dollar amount is shown.

Based on the responses, the average expressed willingness of the public to pay to solve global warming is approximately $\$ 6.50$ per month. Statistical analyses suggest that while concern about the environment increases willingness to pay, neither household income nor the monthly electric bill has a significant impact on expressed willingness to pay [1].

The survey included an experiment that further explores price sensitivity. The experiment measures the effect of price and electricity production information on public preference for alternative approaches to address global warming as it relates to electricity production. The question gave respondents seven choices for addressing global warming and asked them to choose the one that they preferred. About half of the survey respondents ( $\mathrm{n}=691$ ) received no information and about half of the survey respondents $(n=614)$ received the information about the fuels used to produce electricity in 2002 [6] plus the following cost information [4, 7]:

- Using coal and natural gas, the typical family pays $\$ 1,200$ per year for electricity.

- Using all nuclear power would emit no carbon dioxide and would increase electricity cost for families to $\$ 2,400$ per year.

- Using carbon sequestration along with coal and natural gas would reduce carbon dioxide emissions by $90 \%$ and would also increase electricity costs to $\$ 2,400$ per year.

- Using renewables (solar and wind power) would increase annual electricity costs to $\$ 4,000$

This price information was not meant to be exact, but was meant to clearly distinguish relative costs between the technologies to determine whether the public maintained their support for renewable energy in the face of higher prices. It should be noted that on a regional or local level, there are economically competitive sources of renewable energy (wind turbines, hydropower, etc.) that are cheaper than the costs described above.

Table 3 shows the responses for the two groups. 
Table 3. Response to: How can we best address the issue of global warming as it relates to electricity production?

\begin{tabular}{lcc} 
Method to address global warming & No information, $\mathbf{n = 6 9 1}(\mathbf{\%})$ & Information, $\mathbf{n = 6 1 4}(\mathbf{\%})$ \\
\hline $\begin{array}{l}\text { Do nothing. We can live with global } \\
\text { warming. }\end{array}$ & 4 & 5 \\
$\begin{array}{l}\text { Invest in research and development. A } \\
\text { new technology will solve global }\end{array}$ & 24 & 28 \\
$\begin{array}{l}\text { warming. } \\
\begin{array}{l}\text { Continue using fossil fuels but with } \\
\text { capture and storage of carbon dioxide. }\end{array}\end{array}$ & 6 & 16 \\
$\begin{array}{l}\text { Expand nuclear power. } \\
\begin{array}{l}\text { Expand renewables (solar and wind } \\
\text { power). }\end{array}\end{array}$ & 7 & 11 \\
$\begin{array}{l}\text { Reduce electricity consumption, even if } \\
\text { it means lower economic growth. }\end{array}$ & 49 & 25 \\
$\begin{array}{l}\text { Do nothing. There is no threat of global } \\
\text { warming. }\end{array}$ & 7 & 10 \\
\hline
\end{tabular}

This experiment takes advantage of the fact that the public is generally supportive of renewable sources of electricity but largely unaware of the costs associated with these sources. If the public were more aware of the cost difference between renewable electricity and current electricity sources, the difference between the two cases would not be as striking. Similarly, if the public were more aware that nuclear power does not produce carbon dioxide then they might be more willing to support the technology.

Table 3 shows that respondents moved away from the most expensive option when presented with cost and emissions data. This suggests there is a limit to willingness to pay as the price of the option increases. Moreover, survey responses to questions on willingness to pay are known to overstate actual behavior when asked to pay significant sums for environmental amenities. Thus, one would expect an even more precipitous decline in public support if they were aware of such a large discrepancy in price and able to choose the cheaper option.

The results of this experiment suggest that the public is sensitive to the price of options directed at solving global warming. In the no information case, $49 \%$ of respondents choose renewable energy sources. When provided price information showing that the annual cost of switching to an all-renewable electricity portfolio is over three times the current fossil fuel portfolio cost, the number of respondents choosing renewable electricity drops in half to $25 \%$. This replicates the results of the MIT Future of Nuclear Power study [4]. Note that in Table 3, even in the case with information, renewable electricity retains a considerable amount of support relative to the other options.

There is no clear winner when respondents shift away from renewable electricity. When respondents receive cost information, they do not move to a particular alternative. Reduction in consumption fares slightly better in the information case but may not have been embraced because it was put in terms of the tradeoff between a reduction in consumption and lower economic growth.

The largest increase in support from the no information case to the information case is for fossil fuel-based electricity with carbon dioxide capture and storage. There is a $195 \%$ increase in the number of respondents choosing fossil fuels with carbon capture and storage when price and current production information are given. It is not clear if this shift is in response to the technology or to the cost. Respondents may be reacting to the idea of using fossil fuels as opposed to the idea of using carbon capture and storage.

\section{Implications for Public Acceptance}

The survey shows that a very small portion of the public has heard of CCS and a negligible number can correctly identify what environmental problem it addresses. When asked in our survey if they would consider using this technology to address global warming, 38\% said they were not sure if they would or would not use the technology. This lack of awareness and uncertainty suggests that the public will only slowly begin to develop opinions about 
CCS over the coming years and decades (assuming the number of experimental, demonstration, and commercial operations continue to increase). Early successes or failures will therefore likely have important implications for public perceptions.

The results of the survey do not suggest specific actions to increase awareness of CCS; the number of respondents that had heard of CCS was so small that it was impossible to draw clear conclusions about public perception towards the technology. However, taking a step away from CCS, the survey does provide some ideas about attitudes toward climate change and climate change mitigation.

While the survey shows that public generally understands correctly that automobiles, factories, and coal burning power plants emit $\mathrm{CO}_{2}$, the survey also shows the public is confused about whether nuclear power plants, home heating, and oceans increase or decrease $\mathrm{CO}_{2}$. These results suggest that there are serious gaps in public understanding of the sources that release $\mathrm{CO}_{2}$ to the atmosphere and that these gaps affect not only a new technology such as CCS but also such longstanding, visible technologies as nuclear power plants [4,5]. A program to increase awareness of CCS should not assume that the public is aware of the effect of older, better-established technologies on climate change.

It is important to note that the technologies that received the greatest recognition and popular support in the absence of information were renewable energy technologies. The experiment of providing electricity cost and production data to half of the sample population showed that the public is largely uninformed about the cost of renewable electricity although a significant fraction continues to support renewable energy when presented with information that shows that it is more costly than other options. This experiment suggests that accurate price information is essential to the public making a decision about climate change. Awareness and understanding of technological options might not be as essential as awareness of the cost of technological options.

Over the next years and decades, the public will likely begin to form opinions about CCS. It is probable that the influence of popular public opinion on CCS policy will be limited in the early stages of development. Commercial CCS projects are already underway in parts of the world and there are a number of experimental and demonstration projects underway in the United States. Historically, policy makers in the government and the energy industry make the decisions about research allocation and facility placement without much public input [8]. Public perceptions usually only enter the debate when there is local opposition to project siting. The current lack of saliency and public awareness implies that engaging environmental groups or community groups that are just beginning to become aware of the issue will be more effective in the near term than trying to involve the general public.

The not-in-my-backyard (NIMBY) effect (or not-under-my-backyard (NUMBY) effect as Huijts calls it [9]) will probably have a stronger impact on the development of CCS than the general public sentiment. In the early stages of development, local residents will be asked to take a cost for the global good. There will be diffuse benefits and concentrated costs, a situation where opposition is traditionally very effective.

Communicating the risks of CCS to local residents will be a difficult task. Researchers from Carnegie Mellon University and the Georgia Institute of Technology recently published a book on communicating risk [10]. One danger they identify is that the risk communicator operates from a biased position. While developing methodologies for communicating the risks of CCS, one has to be aware of internal biases and the fact that local communities might be asked to bear a risk while the global society benefits.

Although the survey attempted to examine the relationship between those that considered global warming to be a serious problem and willingness to pay for action to reduce climate change, it is too early to tell whether, for example, an education campaign on the risks of climate change would noticeably increase support for CCS or reduce local opposition in future efforts to site $\mathrm{CO}_{2}$ storage facilities. Wind power has generated considerable local opposition in spite of widespread recognition that wind energy would mitigate climate change as reflected in our survey and others. Given the diffuse nature of the benefits to the climate, local concerns will need to be addressed through a process seen as fair by the local community.

Recent surveys of public attitudes toward CCS suggest that an open decision-making process with clear avenues for introducing public comments and concerns will aid in the acceptance of the technology [9, 11]. Keeping the 
process open will help address some of the concerns that the government and industry working alone might not recognize or appreciate.

\section{Conclusions}

A number of public surveys conducted over the past 10 years show belief in global climate change and support for action to address it $[10,12,13]$. However, the public is uncertain about what actions are available to address climate change. In fact, the public is uncertain about what exactly is causing climate change and often links climate change to increased pollution as opposed to increased concentrations of greenhouse gases.

The important conclusions from the survey are:

- The environment is not a pressing concern for the majority of the public.

- Global warming is not the top environmental concern (even among those who are concerned about the environment).

- Very few people in the United States have heard of CCS.

- Those who have heard of CCS are no more likely to know what environmental concern it addresses than those who have not heard of CCS.

- A large portion of the public supports investment in renewable energy technologies but that support decreases when cost information that suggests they are more expensive than other climate mitigation technologies is provided.

\section{Acknowledgements}

We would like to acknowledge the generous support of the Alliance for Global Sustainability and the Carbon Sequestration Initiative at MIT who sponsored this research.

\section{References}

1. Curry, T.E. 2004. Public Awareness of Carbon Capture and Storage: A Survey of Attitudes toward Climate Change Mitigation. Master's Thesis, Cambridge, MA: MIT. Available at:

http://sequestration.mit.edu/bibliography/policy.html.

2. Knowledge Networks. 2003. Field Report: Herzog Energy Study. Menlo Park, CA: Knowledge Networks Internal document.

3. The Polling Report. 2004. Environment. The Polling Report, Inc. Accessed April 2004. Available at: http://www.pollingreport.com/enviro.htm.

4. Deutch, J., E. Moniz, S. Ansolabehere, M. Driscoll, P.E. Gray, J.P. Holdren, P.L. Joskow, R.K. Lester and N.E. Todreas. 2003. The Future of Nuclear Power: An Interdisciplinary MIT Study. Cambridge, MA: MIT. Available at: http://web.mit.edu/nuclearpower/.

5. European Commission Directorate General for Research. 2003. EUROBAROMETER - ENERGY: Issues, Options and Technologies, Science and Society. , Report EUR20624, Luxembourg: European Communities. Available at: http://europa.eu.int/comm/research/energy/pdf/eurobarometer_energy en.pdf.

6. Energy Information Agency. 2003. Electricity Net Generation. Washington, DC: National Energy Information Center. Available at: http://www.eia.doe.gov/emeu/aer/txt/ptb0802a.html.

7. David, J. and H. Herzog. 2000. The Cost of Carbon Capture. Presented at the Fifth International Conference on Greenhouse Gas Control Technologies, Cairns, Australia, August 13-16. Collingwood, Australia: CSIRO Publishing. Proceedings available at: http://www.ieagreen.org.uk/ghgt5.htm. Paper available at: http://sequestration.mit.edu/pdf/David and Herzog.pdf.

8. Conn, W.D. 1983. Energy and Material Resources: Attitudes, Values, and Public Policy. Washington, DC: Westview Press for the American Association for the Advancement of Science. 
9. Huijts, N. 2003. Public Perception of Carbon Dioxide Storage. Master's Thesis. Eindhoven, The Netherlands: Eindhoven University of Technology

10. Morgan, M.G., B. Fischhoff, A. Bostrom and C.J. Atman. 2002. Risk Communication: A Mental Models Approach. New York: Cambridge University Press.

11. Shackley, S., C. McLachlan and C. Gough. 2004. Public Perceptions of Carbon Capture and Storage. Working Paper Number 44. . Manchester, UK: Tyndall Center for Climate Change Research. Available at: http://www.tyndall.ac.uk/publications/working_papers/wp44.pdf.

12. Kempton, W., J.S. Boster and J.A. Hartley. 1995. Environmental Values in American Culture. Cambridge, MA: The MIT Press.

13. Leiserowitz,, A. 2003. American Opinions on Global Warming. University of Oregon Survey Research Laboratory. Accessed April 2004. Available at: http://osrl.uoregon.edu/projects/globalwarm. 